\title{
Simvastatin Potentiates the Antihyperglycemic, Antidyslipidimic and Antioxidative Effect of Glibenclamide on Alloxan-Induced Diabetic Rats
}

\author{
Mst. Marium Begum, A. F. M. Towheedur Rahman, Saiful Islam, Md. Asaduzzaman, \\ Hazrat Ali, Yusuf Ali, Shaheda Zannah, A. H. M. Khurshid Alam, \\ Aziz Abdur Rahman, Mamunur Rashid* \\ Department of Pharmacy, University of Rajshahi, Rajshahi, Bangladesh \\ Email: ${ }^{*}$ mamun69jp@yahoo.com
}

Received 11 September 2014; revised 8 October 2014; accepted 18 October 2014

Copyright (C) 2014 by authors and Scientific Research Publishing Inc.

This work is licensed under the Creative Commons Attribution International License (CC BY).

http://creativecommons.org/licenses/by/4.0/

(c) (i) Open Access

\section{Abstract}

The aim of the current study is to investigate the effect of combination of glibenclamide; an antidiabetic drug and simvastatin; a HMG-CoA reductase inhibitor on long-term (four weeks) alloxaninduced diabetes rats (ADRs). Methods: Alloxan $(120 \mathrm{mg} / \mathrm{kg}$ body weight, BW) was injected intraperitonially (i.p.) in rats. At first alloxan $(120 \mathrm{mg} / \mathrm{kg} \mathrm{BW})$ induced diabetic rats were treated with single dose of glibenclamide $(1.2 \mathrm{mg} / 70 \mathrm{~kg} \mathrm{BW})$ and simvastatin $(10 \mathrm{mg} / 70 \mathrm{~kg} \mathrm{BW})$ for two weeks. Then fixed dose combinations of glibenclamide $(0.6 \mathrm{mg} / 70 \mathrm{~kg} \mathrm{BW})$ and simvastatin $(5 \mathrm{mg} / 70 \mathrm{~kg}$ BW) were injected along with those of two drugs for four weeks. Results: At first it was found that glibenclamide reduced significant amount of glucose in blood, but it had no significant effect on lipid profile on short term (two weeks) ADRs. In contrast, simvastatin had no effect on blood glucose level, whereas it significantly reduced total cholesterol (TC), triglycerides (TG) and low density lipoprotein cholesterol (LDL-C) and increased significant amount of high density lipoprotein cholesterol (HDL-C). However, pathological changes of pancreas's Islets of Langerhans were observed only after long-term (four weeks) induction of alloxan in rats. The inhibitory effect of combination therapy on blood glucose, TC, TG and LDL-C level was higher than those of monotherapy alone on long term ADRs. In addition, treatment with combination therapy on long term ADRs showed higher amount of HDL-C level and super oxide dismutase and catalase enzyme activity than those with monotherapy. They also decreased serum glutamic pyruvic transaminase (SGPT) and Serum glutamic oxaloacetic transaminase (SGOT) level. Administration of simvastatin recovered Langerhans cells from shrinkage whereas glibenclamide displayed slight recovery. But the

\footnotetext{
${ }^{*}$ Corresponding author.
}

How to cite this paper: Marium Begum, M., et al. (2014) Simvastatin Potentiates the Antihyperglycemic, Antidyslipidimic and Antioxidative Effect of Glibenclamide on Alloxan-Induced Diabetic Rats. Pharmacology \& Pharmacy, 5, 1059-1069. 
combination therapy showed complete recovery of Langerhans cells as compared with diabetic rats. Conclusion: Our present findings suggest that treatment of glibenclamide in combination with simvastatin may be more effective than mono-therapy for preventing diabetes in rats. It may also suggest that this combination may have some beneficial effects on reducing cardiovascular risks from long term diabetes in rats.

\title{
Keywords
}

\author{
Diabetes, Combination Therapy, Gibenclamide, Simvastatin, Beneficial Effects
}

\section{Introduction}

Diabetes mellitus (DM) can be defined as a metabolic disorder of carbohydrate, fat, and protein metabolism which ultimately results in hyperglycemia due to the defects in insulin secretion, insulin action, or both [1]. Diabetes is usually accompanied by increased production of free radicals [2]-[4] or impaired antioxidant defenses [5], and this oxidative stress ultimately leads to apoptosis or myocardial cell injury, impair pancreatic beta cells and dysfunction by alteration of gene expression and modification of cellular responses [6]. Hypercholesterolemia and hypertriglyceridemia are independent risk factors that alone or together can accelerate the development of atherosclerosis and progression of atherosclerotic lesions [7] [8].

At present, the treatment of diabetes mainly involves a sustained reduction in hyperglycemia by the use of biguanides, thiazolidinediones, sulfonylureas D-phenylalanine and $\alpha$-glucosidase inhibitors in addition to insulin. However, due to unwanted side effects, the efficacies of these compounds are debatable and there is a demand as well as continuation of these drugs for the treatment of diabetes with cardiovascular diseases (CVDs) [9]. Moreover, long-term induction of diabetes without any lipid lowering drug leads to the risk of CVDs. Hence, combination therapy has been suggested as a rich source of potentially useful antidiabetic and hypolipidemic drugs.

The attributed antihyperglycemic and antidyslipidemic effects of this combination therapy are due to their ability to restore the function of pancreatic tissues by causing an increase insulin output, or to inhibit the intestinal absorption of glucose, or to facilitate the metabolites in insulin dependent processes [10], and their ability to inhibit the cholesterol biosynthetic pathway by inhibiting the enzyme HMG-CoA reductase [11]. Hence, treatment with combination therapy has an effect on protecting $\beta$-cells and smoothing out fluctuation in glucose level and cholesterol biosynthetic pathway. Therefore, the present study was aimed at providing a strong view on experimental studies in animals, to find out the most effective and commonly used hypoglycemic and lipid lowering drugs combination on long-term alloxan induced diabetes in rats.

\section{Materials and Methods}

\subsection{Animal Studies}

All protocols for the animal experiments were reviewed and approved by the Animal Care and Use Committee of Institute of Biological Science, University of Rajshahi. Long-Evans male rats weighing about 200 - 220 g, aged 2 months, were purchased from animal's house of International Centre for Diarrheal Disease Research, Bangladesh (ICDDRB). Prior to commencement of the experiments, all the rats were acclimatized to the new environmental condition for a period of one week. During the experimental period, the rats were kept in a well ventilated animal house at room temperature and were supplied standard pellets from ICDDRB and fresh drinking water. The rats were kept in cages and maintained with natural 12 hour light and dark cycle. In both protocols (two weeks for short-term and four weeks for long-term), alloxan (Loba Chemiie, Bombay, India) was injected intra-peritonially (i.p.) in rats at a dose of $120 \mathrm{mg} / \mathrm{kg}$ body weight (BW). At first we treated alloxan induced diabetic rats with single dose of glibenclamide $(1.2 \mathrm{mg} / 70 \mathrm{~kg} \mathrm{BW})$ and simvastatin $(10 \mathrm{mg} / 70 \mathrm{~kg} \mathrm{BW})$ for two weeks. For four weeks treatment protocol again we treated alloxan induced diabetic rats with single dose of glibenclamide $(1.2 \mathrm{mg} / 70 \mathrm{~kg} \mathrm{BW})$, single dose of simvastatin $(10 \mathrm{mg} / 70 \mathrm{~kg} \mathrm{BW})$ and fixed dose combinations of glibenclamide (0.6 mg/70kg BW) and simvastatin (5 mg/70kg BW) together. 


\subsection{Grouping of Experimental Rats}

Within 96 Long Evans male rats, 12 rats were randomly assigned into group A, C and F, 4 rats in each group for glucose tolerance test. 12 Long Evans rats were randomly assigned into 3 groups A, B, and C (4 rats in each group), for repeated dose treatment for one week for blood glucose test. For two weeks protocol, a total number of 32 rats were assigned into 4 groups A, B, C and D (8 rats in each group) for the determination of blood glucose and lipid profile. For four weeks protocol, a total number of 40 rats were assigned into 5 groups A, B, C, D and $\mathrm{E}$ (8 rats in each group) for the determination of blood glucose, lipid profile, glycogen content, antioxidant activity and histological studies.

Group A: Normal Control

Group B: Diabetic/Alloxan Control

Group C: (Diabetic + Glibenclamide) or Glibenclamide Control

Group D: (Diabetic + Simvastatin)/or Simvastatin Control

Group E: Diabetic + Combination (Glibenclamide + Simvastatin) Control

Group F: Glucose Control

\subsection{Measurement of Glucose Level}

Glibenclamide and simvastatin both drugs were administered daily in alloxan-induced diabetic rats for two weeks treatment protocols. Again glibenclamide, simvastatin and combination of both drugs were administered daily in alloxan-induced diabetic rats for four weeks treatment protocols. After two and four week's treatment with drugs, blood glucose level was determined two hours after last dose using Glucometer (One Touch Horizon, USA).

\subsection{Measurement of Lipid Profile}

After completing the treatment of drugs, the rats were anesthetized with sodium phenobarbital. Then abdominal skin was cut and thoracic artery was opened. Finally, 3 - $5 \mathrm{ml}$ of blood was collected directly from thoracic artery by syringes. The blood was centrifuged at $4000 \mathrm{rpm}$ for 10 minutes and the serum was obtained. Serum lipid profile, such as total cholesterol (TC), triglyceride (TG), low density lipoprotein-cholesterol (LDL-C) and high density lipoprotein-cholesterol (HDL-C), was assessed using diagnostic kits (Human, Germany).

\subsection{Evaluation of Super Oxide Dismutase and Catalase Enzyme Activity}

After the experimental period, the animals were sacrificed; liver was isolated, homogenized in chilled Tris buffer at a concentration of $10 \%(\mathrm{w} / \mathrm{v})$. The homogenate was centrifuge at $4000 \mathrm{rpm}$ for 15 minutes in cold centrifuge and supernatant was assayed for Superoxide dismutase (SOD) and catalase activity.

The catalase activity was assayed by the method of Sinha [12]. In brief, the incubation mixture contained in a final volume of $2.0 \mathrm{ml}, 0.1 \mathrm{ml}$ of diluted homogenate supernatant, $1.0 \mathrm{ml}$ of $0.01 \mathrm{M}$ phosphate buffer and $0.4 \mathrm{ml}$ of distilled water to which $0.5 \mathrm{ml}$ of $2.0 \mathrm{M} \mathrm{H}_{2} \mathrm{O}_{2}$ solution was added to initiate the reaction, while the $\mathrm{H}_{2} \mathrm{O}_{2}$ solution was left out in control tubes. After incubating for $1 \mathrm{~min}$ at $37^{\circ} \mathrm{C}$ the reaction was stopped by addition of 2 $\mathrm{ml}$ of potassium dichromate acetic acid reagent (5\% potassium dichromate and glacial acetic acid mixed in a 1:3 ratio). The samples were kept in boiling water bath for 15 minutes, finally cooled and the absorbance measured at $570 \mathrm{~nm}$ against control.

SOD activity was determined by the method of Misra and Fridovich [13]. $3.0 \mathrm{ml}$ reaction mixture contains of $1.5 \mathrm{ml}$ of $0.1 \mathrm{M}$ carbonate-bicarbonate buffer, $\mathrm{pH}$ 10.3; $0.1 \mathrm{ml}$ of $30 \mathrm{mM}$ EDTA, suitable aliquot of enzyme preparation and water to make up the volume to $2.94 \mathrm{ml}$. The reaction was started by addition of $0.06 \mathrm{ml}$ of 15 $\mathrm{mM}$ epinephrine. Changes in absorbance were recorded at $48 \mathrm{~nm}$ for one minute at $15 \mathrm{sec}$ interval. Control consisting of all the ingredients, except enzyme preparation, was run simultaneously. One unit of enzyme activity has been defined to cause $50 \%$ inhibition of auto-oxidation of epinephrine by $1.0 \mathrm{ml}$ of homogenate.

\subsection{Measurement of SGPT and SGOT Level}

After completing the treatment of drugs, the rats were at first anesthetized with sodium phenobarbital. Then abdominal skin was cut and thoracic artery was opened. Finally 3 - 5 ml of blood was collected directly from tho- 
racic artery by syringes. The blood was centrifuged at $4000 \mathrm{rpm}$ for 10 minutes and the serum was obtained. The blood serum which was collected and serum is used for testing the serum glutamic pyruvate transaminase (SGPT) and serum glutamic oxaloacetate transaminase (SGOT) levels. The concentrations were analyzed by taking absorbance by UV spectrophotometer, using diagnostic kits (Human, Germany). These tests are carried out as the parameter of liver dysfunction indices.

\subsection{Histological Analysis}

Histological studies were performed for the investigation of pancreatic beta cell recovery. In brief one section was obtained from each pancreas, and mounted on slides and stained with hematoxylin and eosin. To evaluate the extent of pancreacyte recovery, cross-sectional images of pancreacyte were scanned at $\times 200$ magnifications. All images were taken using a KRUSS (A Kruss Optronic, Humburg, Germany).

\subsection{Statistical Analysis}

The results were expressed as mean \pm SEM using Graph Pad Prism (version 4.0) computer program (Graph pad Software San Diego, CA, USA). We used a one-way analysis of variance (ANOVA), followed by Dunnett's post-hoc test or students paired or unpaired $t$-test where appropriate. The statistical method applied in each analysis was described in each figure. Results were considered to be significant when p values were less than $0.05(\mathrm{p}<0.05)$.

\section{Results}

The effect of drug alone (glibenclamide/simvastatin) and combination (glibenclamide and simvastatin) on the parameters of blood glucose level, lipid profile (TC, TG, LDL-C, HDL-C), antioxidant property and histopathology of pancreas Islets of Langerhans were performed for both short and long-term alloxan induced diabetic rats (ADRs).

\subsection{Effect of Glibenclamide and Simvastatin on Blood Glucose Level in Short-Term ADRs}

Intraperitoneal injection of alloxan in rats significantly increased blood glucose level (16.40 mmol/lit) when compared with normal rats $(6.30 \mathrm{mmol} /$ lit) (Figure 1(a)). To clarify the individual effect of glibenclamide and simvastatin on blood glucose level, we estimated blood glucose level after two weeks treatment of glibenclamide and simvastatin on ADRs. Glibenclamide alone significantly decreased blood glucose level from $16.40 \pm$ 0.12 to $7.45 \pm 0.10 \mathrm{mmol} /$ lit, whereas simvastatin alone failed to reduce significant amount of blood glucose level when compared with ADRs (Figure 1(a)).

\subsection{Effect of Glibenclamide and Simvastatin on Lipid Profile in Short-Term ADRs}

Short-term induction of diabetes by alloxan in rats significantly altered lipid profile when compared with normal rats (Figures 1(b)-(e)). To make clear the individual effect of glibenclamide and simvastatin on lipid profile, we examined TC, TG, LDL-C and HDL-C level after two weeks treatment of glibenclamide and simvastatin in diabetic rats. After two weeks treatment by drugs, we found that both glibenclamide and simvastatin reduced TC level 4.27\% and 42.58\% (Figure 1(b)), TG level 8.39\% and 32.17\% (Figure 1(c)), and LDL-C level 4.17\% and 27.32\% (Figure 1(d)), whereas they increased HDL-C level 9.35\% and 51.07\% (Figure 1(e)), respectively when compared with diabetic rats.

We performed histological analysis in ADRs to check whether or not short-term induction could recover Langerhans cell of islets of pancreas. Interestingly, we could not observe any change on pancreas Islets of Langerhans morphology in diabetic rats (data were not shown).

\subsection{Effect of Combination Therapy on Blood Glucose Level in Long-Term ADRs}

Long-term induction of diabetes by alloxan in rats increased blood glucose level (33.75 mmol/lit) twice when compared with short-term induction of diabetes (16.40 mmol/lit) (Figure 1(a) and Figure 2(a)). To investigate the effect of mono and combination therapy on blood glucose level in long-term ADRs, we examined blood glucose level after four weeks treatment of glibenclamide and simvastatin alone and combination of both in di- 


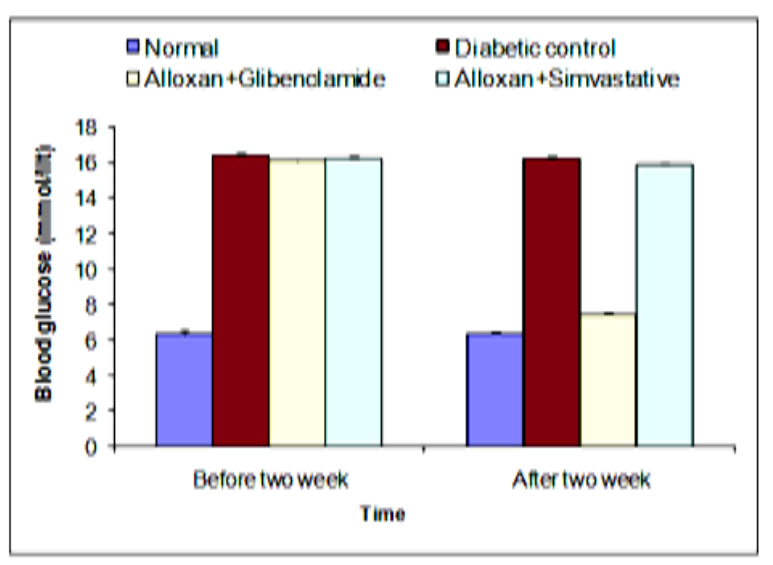

(a)

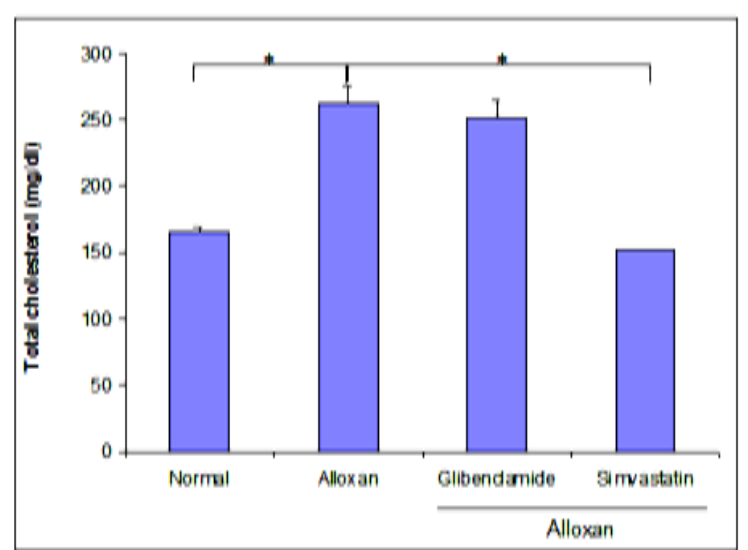

(b)

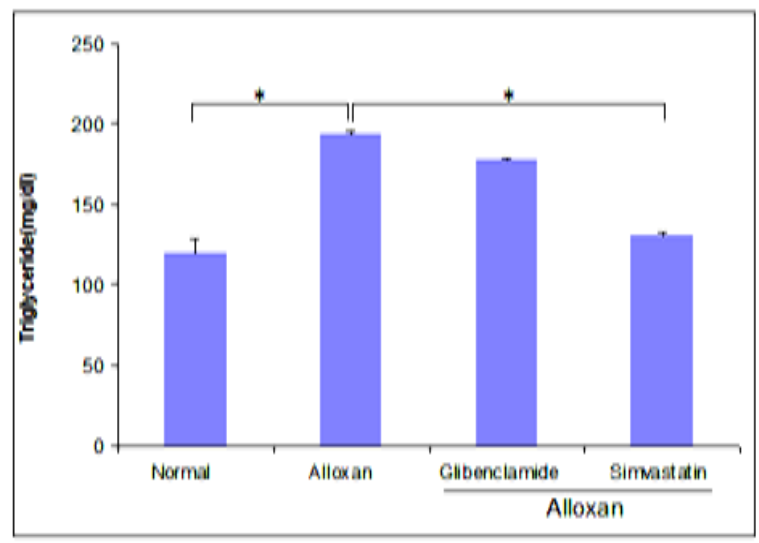

(c)

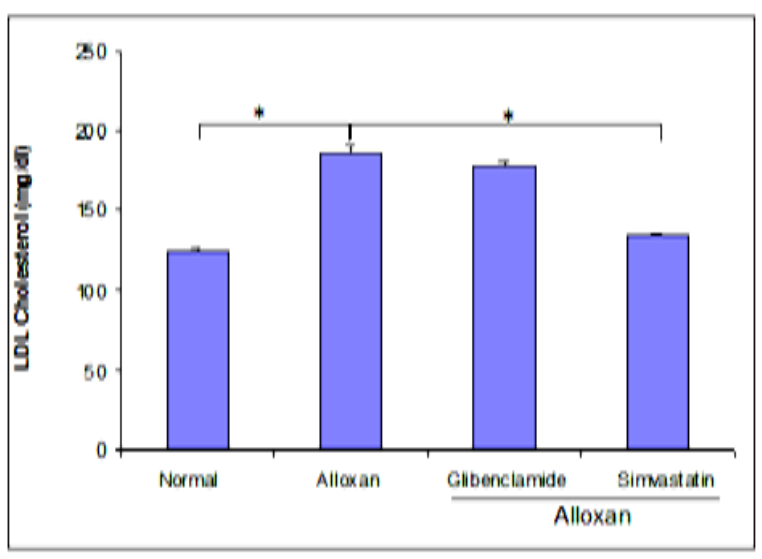

(d)

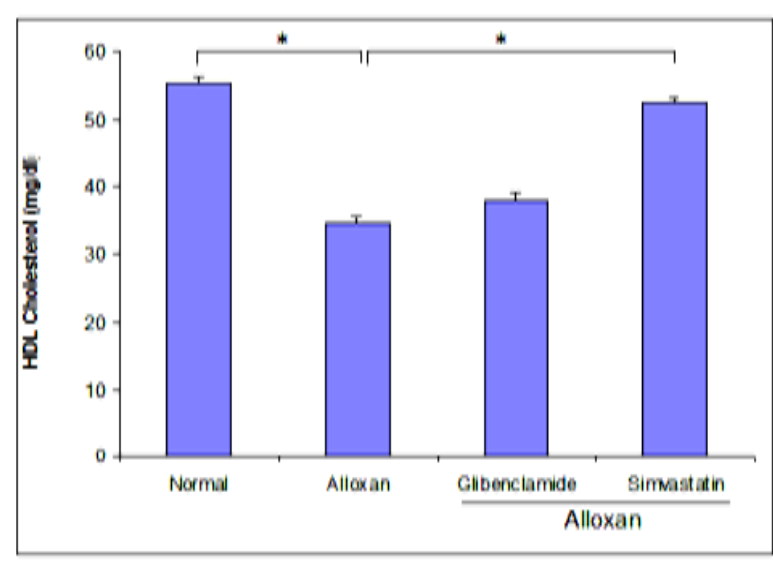

(e)

Figure 1. Effect of glibenclamide and simvastatin for two weeks on blood glucose level and lipid profile in short-term alloxan-induced diabetic rats. (a) Blood glucose level was estimated after two weeks treatment with glibenclamide and simvastatin in alloxan-induced diabetic rats; (b)-(e) represented the estimation of TC, TG, LDL and HDL-C levels, respectively. All values were presented as mean $\pm \mathrm{SEM} ; \mathrm{n}=6$ in each group, ${ }^{*} \mathrm{p}<0.05$ compared to alloxan-induced diabetic rats (ANOVA followed by Dunnett's test).

abetic rats. After four weeks treatment, glibenclamide alone and combination of both significantly decreased blood glucose level from $33.75 \pm 1.65$ to $6.37 \pm 0.08 \mathrm{mmol} / \mathrm{lit}$ and $33.75 \pm 1.65$ to $5.80 \pm 0.07 \mathrm{mmol} / \mathrm{lit}$, respectively when compared with diabetic rats. Simvastatin alone failed to reduce significant amount of blood glucose level when compared with diabetic rats (Figure 2(a)). 


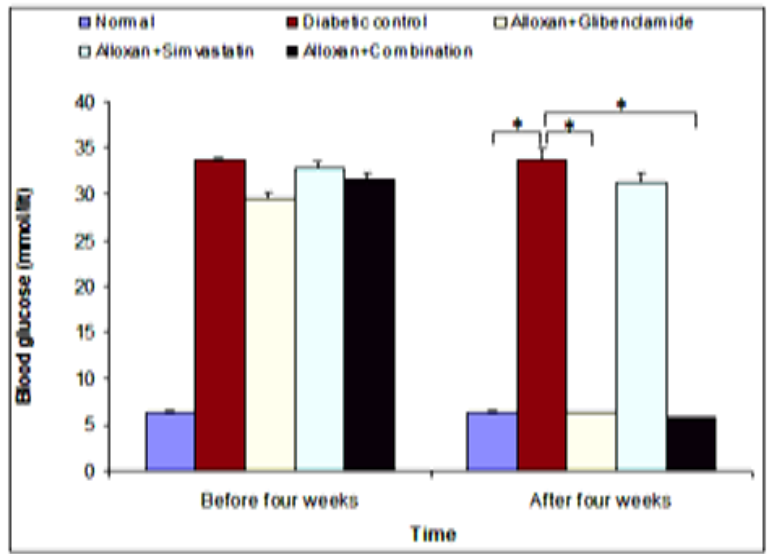

(a)

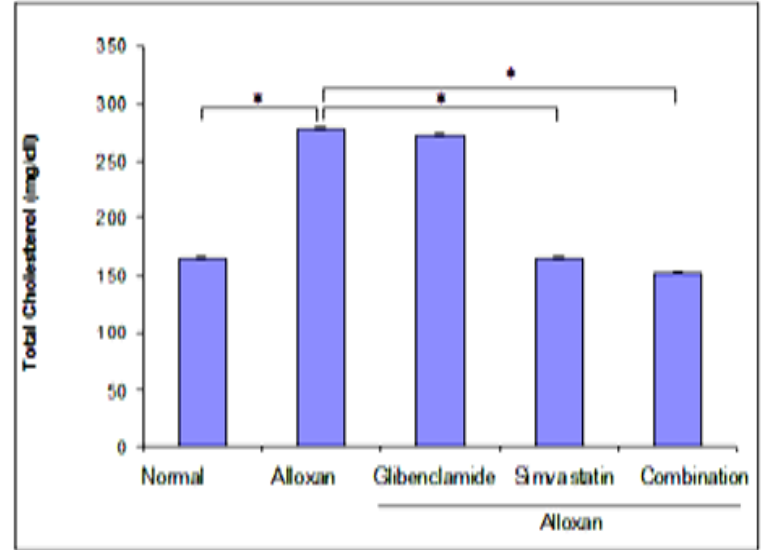

(b)

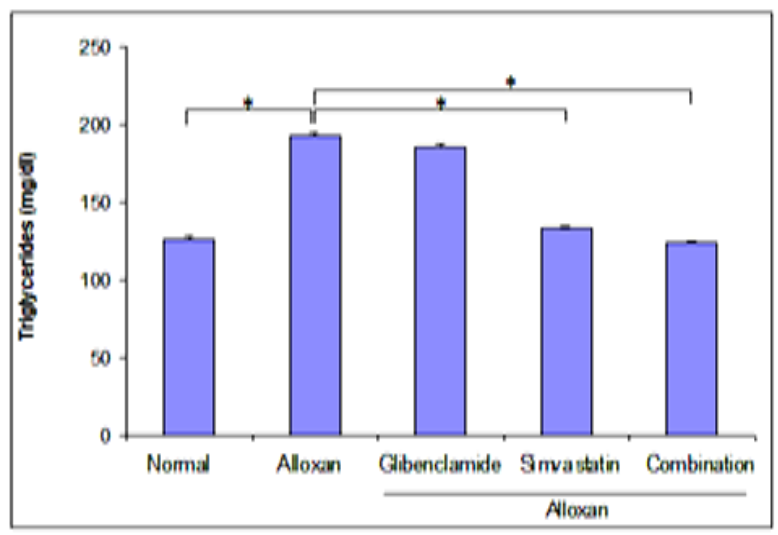

(c)

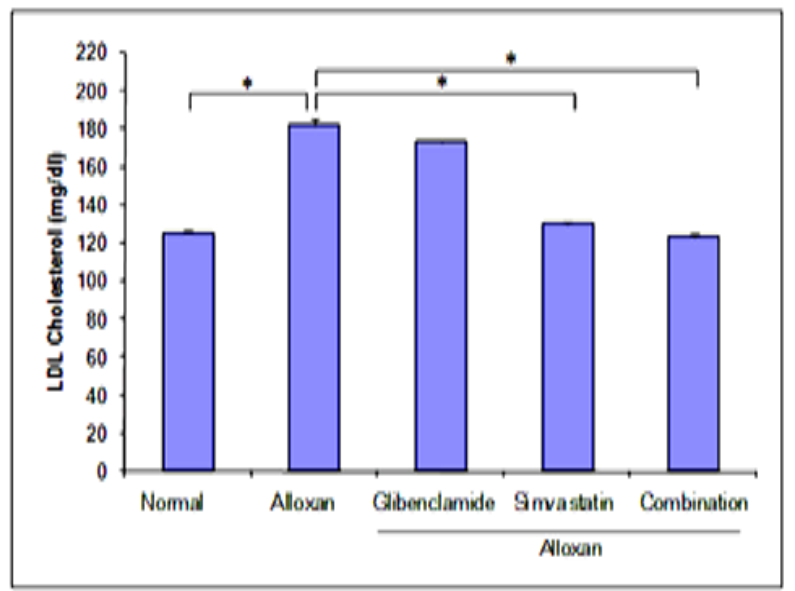

(d)

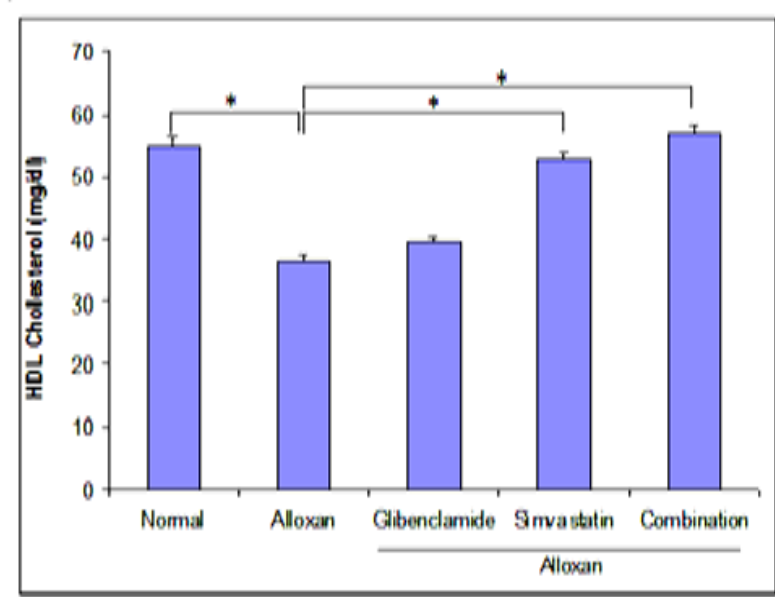

(e)

Figure 2. Effect of glibenclamide alone, simvastatin alone and combination of both for four weeks on blood glucose level and lipid profile in long-term alloxan-induced diabetic rats. (a) Blood glucose level was estimated after four weeks treatment with glibenclamide alone, simvastatin alone and combination of both on long-term alloxan-induced diabetic rats; (b)-(e) represented the estimation of TC, TG, LDL and HDL-C levels, respectively. Data were presented as mean \pm SEM; $n=6$ in each group, ${ }^{*} \mathrm{p}<0.05$ and ${ }^{* *} \mathrm{p}<0.01$ compared to alloxan-induced diabetic rats (ANOVA followed by Dunnett’s test).

\subsection{Effect of Combination Therapy on Lipid Profile in Long-Term ADRs}

To clarify the effect of mono and combination therapy on lipid profile, we examined TC, TG, LDL-C and HDL$\mathrm{C}$ level, after four weeks treatment with glibenclamide and simvastatin alone and combination of both in long- 
term ADRs. After four weeks treatment, it was found that glibenclamide, simvastatin and combination of both reduced TC level 2.24\%, 40.55\% and 45.05\% (Figure 2(b)), TG level 3.51\%, 30.68\% and 35.76\% (Figure 2(c)), and LDL-C level 4.80\%, 28.39\% and 32.23\% (Figure 2(d)), and they increased HDL-C level 8.9\%, 45.89\% and $56.84 \%$ (Figure 2(e)), respectively when compared with diabetic rats. In contrast, the effect of combination therapy on lipid profile was higher than that of mono-therapy alone. Glibenclamide alone did not show any significant effect on lipid profile (Figures 2(b)-(e)).

\subsection{Antioxidative Effect of Combination Therapy on Long-Term ADRs}

The effect of glibenclamide, simvastatin and combination of both drugs on catalase enzyme activity and superoxide dismutase in ADRs was shown in Figure 3(a) and Figure 3(b). After four weeks treatment with glibenlamide, simvastatin and combination of both drugs it was observed that catalase enzyme activity was increased $6.72 \%, 34.97 \%$ and $57.84 \%$ and super oxide enzyme activity was increased $7.25 \%, 86.10 \%$, and $90.67 \%$ respectively in comparison with ADRs. This result revealed that the combination therapy showed better antioxidant activity than mono-therapy in long-term ADRs.

\subsection{Effect of Combination Therapy on Liver Dysfunction Indices Activity on Long-Term ADRs}

The effect of glibenclamide, simvastatin and combination of both drugs on liver dysfunction indices activity in ADRs was shown in Figure 3(c) and Figure 3(d). After four weeks treatment, glibenclamide, simvastatin and combination of both drugs decreased SGPT level at $41.43 \%$, $4.79 \%$ and $54.79 \%$ and SGOT level at $29.23 \%$, $3.98 \%$ and $50.49 \%$ respectively in comparison with ADRs.

\subsection{Effect of Combination Therapy on Pancreas Islets of Langerhans Morphology on Long-Term ADRS}

Injection of alloxan in rats for four weeks significantly shrunk islets of Langerhans in comparison with normal rats (Figure 4). Treatment with glibenclamide significantly recovered Islets of Langerhans from shrinkage compared with ADRs. Simvastatin exhibited slight effects on Langerhans cells recovery. But in case of combination therapy, complete recovery of Langerhans cells towards normal rats as compared with ADRs was reported.

\section{Discussion}

Hypercholesterolemia and hypertriglyceridemia are common complications of diabetes mellitus in addition to hyperglycemia [14]. Diabetes associated dyslipidemia is the major cause of disability in western as well as in developing countries [15]. Treatment of diabetes with commercially available drugs possesses some degree of adverse effects. Therefore, the search for new, safe and easy to administer drugs remains a top priority. This work has evaluated the effect of new combination therapy of glibenclamide and simvastatin on diabetes in experimental animal of rats, and also on other important biochemical parameters, such as lipid profile, oxidative properties, liver dysfunction indices, morphology of pancreas Islets of Langerhans cells which caused CVD after long-term induction of diabetes.

In the present study, diabetes was induced in rats by injecting alloxan intraperitoneally [16]. Alloxan, a cytotoxic agent, induced diabetes in a wide variety of animal species by damaging insulin secreting $\beta$-cell, resulting in decrease of endogenous insulin release, which paved the way for the decrease utilization of glucose by the tissues.

\subsection{Effect of Mono-Therapy and Combination Therapy on Blood Glucose Level}

The present study showed that glibenclamide produced significant decrease in blood glucose level in alloxaninduced diabetic rats. On the other hand, simvastatin did not produce any significant change of this parameter. Our findings supported the findings of previously published reports [17] [18]. Interestingly, we observed that the combination therapy was more effective for controlling diabetes than the glibenclamide alone in long-term ADRs. However, further studies are needed to clarify the exact mechanism of this effect of combination therapy. 

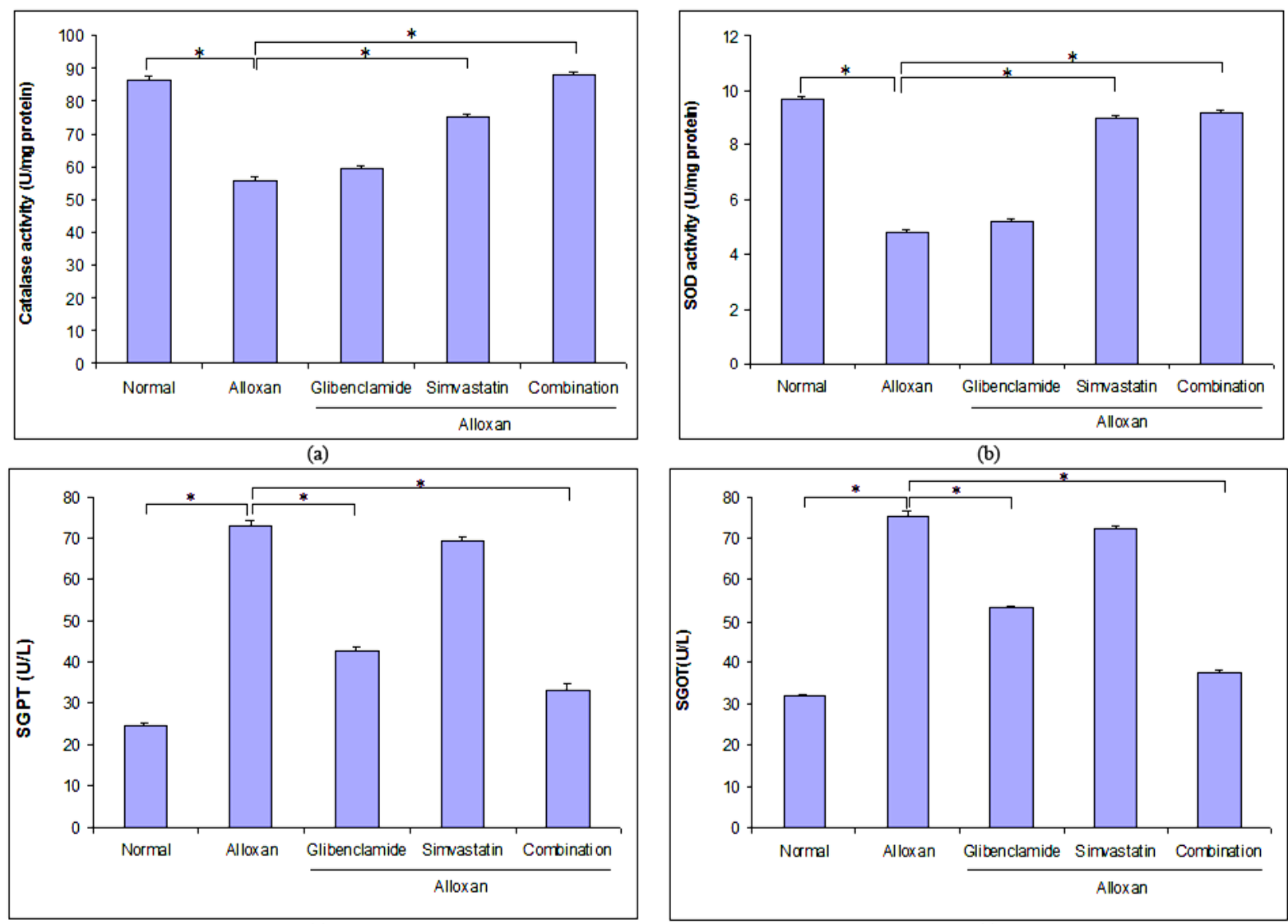

(c)

(d)

Figure 3. Effect of glibenclamide alone, simvastatin alone and combination of both for four weeks on antioxidant superoxide dismutase and catalase activity and liver function indices in long-term alloxan-induced diabetic rats. (a) (b) Percentage of antioxidant enzyme activity was measured, after four weeks treatment with glibenclamide alone, simvastatin alone and combination of both in long-term alloxan-induced diabetic rats. (c) (d) Investigation of the effect of glibenclamide alone, simvastatin alone and combination of both on liver dysfunction indices activity in long-term alloxan-induced diabetic rats. The data were shown as mean \pm SEM, $n=6$ in each case. ${ }^{*} \mathrm{p}<0.05$ and ${ }^{* * *} \mathrm{p}<0.01$ compared to long term alloxan-induced diabetic rats (ANOVA followed by Dunnett's test).

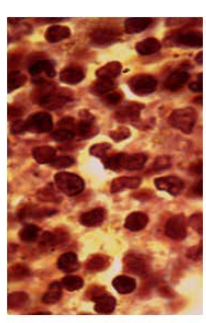

Normal

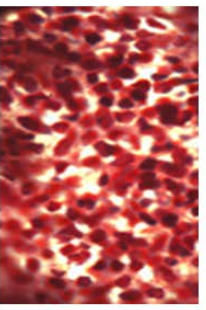

Alloxan

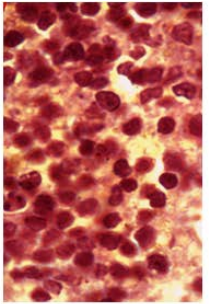

Glibenclamide

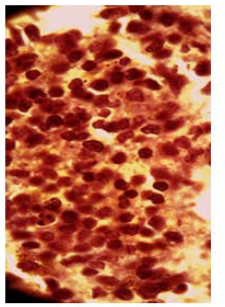

Simvastatin

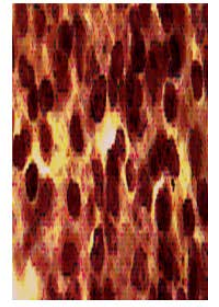

Combination

Alloxan

Figure 4. Microscopic view of the effects of drugs on pancrease Islets of Langerhans morphology after four weeks treatment with glibenclamide alone, simvastatin alone and combination of both in long-term alloxan-induced diabetic rats. $n=6$ in each group.

\subsection{Effect of Monotherapy and Combination Therapy on Lipid Profile}

It was known that the factors which influence the glucose metabolism, under various physiological conditions, can influence lipid metabolism as well [19]. It had also been revealed that TG accumulation increased consider- 
ably in diabetes mellitus [20]. Hypercholesterolemia and hypertriglyceridemia had been reported to occur in diabetic [21]. A significant increase in TC, TG, and LDL-C level; and decrease in HDL-C level observed in our experiment as compared to normal rats in both protocol of diabetic rats. The serum TC, TG, LDL-C levels were significantly decreased and HDL-C level was significantly increased, after two weeks treatment with simvastatin compared to alloxan-induced diabetic rats. We also found similar results on lipid profile after four weeks treatment with simvastatin alone and combination therapy (glibenclamide and simvastatin) compared to alloxan-induced diabetic rats. Interestingly the effect on lipid profile of combination therapy was more substantial than simvastatin alone. Glibenclamide alone was lack of significance effect on lipid profile in both two and four week's studies. Our findings agreed with previously published reports [17] [18].

\subsection{Effect of Combination Therapy on Superoxide Dismutase and Catalase Enzyme Activity}

It has been reported that in diabetic rat superoxide dismutase (SOD) and catalase enzyme activity were usually decreased [22]. It is widely estsblished that hyperglycemia increased oxidative stress [23] and oxidative stress was responsible for the CVD. Free radicals can cause damage to cardinal cellular components such as lipids, proteins, and nucleic acids (e.g. DNA), leading to subsequent cell death. The present study revealed that induction of alloxan in rats for long term significantly decreased antioxidant enzyme (SOD and catalase) activity in comparison with normal rats. Treatment with combination therapy significantly increased these enzyme activities in alloxan induced diabetic rats. Simvastatin alone also significantly increased antioxidant enzyme (SOD and catalase) activity whereas combination therapy showed more significant effect than simvastatin alone. On the contrary, glibenclamide had lack of significance in increasing antioxidant enzyme (SOD and catalase) activity compared with ARDs.

\subsection{Hepatoprotective Effect of Drugs and Combination Therapy}

Associations between elevations in SGPT and SGOT with ADRs have been reported [24]. Insulin resistance, increased pro-inflammatory cytokine production, oxidative stress and mitochondrial dysfunction leading to hepatocyte damage/destruction, have all been posed as important pathophysiological mechanisms [25]. In our study it was observed that there were significant increments in SGPT and SGOT levels in diabetic control group than the normal control group. Treatment with combination therapy (glibenclamide and simvastatin) significantly decreased SGPT and SGOT as a parameter of liver dysfunction indices activity in comparison with ADRs. The inhibitory effect on SGPT and SGOT of combination therapy (glibenclamide and simvastatin) was higher than that of glibenclamide alone compared with ADRs. On the other hand, simvastatin alone had no significant on liver dysfunction indices activity in comparison with ADRs.

\subsection{Effect of Combination Therapy on Pancreas Islets of Langerhans Morphology}

Injection of alloxan in rats significantly shrunk Islets of Langerhans in comparison with normal rats [26]. In our study, the pancreas demonstrated marked shrinkage of Islets of Langerhans cells by the induction of alloxan in comparison with normal rats. Administration of glibenclamide recovered Langerhans cells from shrinkage which was demonstrated earlier where as simvastatin also displayed little recovery of the cells. But in case of combination therapy, noticeable recovery of Langerhans cells was reported.

\section{Conclusion}

Alloxan-induced diabetes in rats represents well-established animal model for both types of diabetes mellitus. Increased production of high levels of oxygen free radicals had been linked to glucose oxidation and non-enzymatic glycation of proteins. Furthermore, characteristic diabetes raised LDL-C level, lowered HDL-C level and elevated TG level which contributed the development of diabetic complications (such as CVD). The present study clearly indicated that the simvastatin potentiated antihyperglycemic, antidyslipidimic and antioxidant property of glibenclamide on ADRs and had the beneficial effects for reducing CVD in vivo. Therefore the present study suggested that simvastatin together with glibenclamide might be effective combination drug in the treatment of diabetes with CVD. However, further study is necessary to clarify the exact mechanism of inhibitory action of combination drugs on diabetes with CVD. 


\section{Acknowledgements}

The authors thank Square Pharmaceuticals Ltd., Bangladesh for its kind gift of simvastatin and glibenclamide.

\section{Declarations}

The author(s) declare(s) that they have no conflict of interest to disclose. This work was carried out as part of M. Pharm study with financial support from the Department of Pharmacy, University of Rajshahi, Bangladesh and NSICT (National Science and Information \& Communication Technology) fellowship, Bangladesh.

\section{References}

[1] Albajali, A.A., Nagi, A.H., Shahzad, M., Ullah, M.I. and Hussain, S. (2011) Effect of Allium sativa L. on Pancreatic $\beta$. Cells Incomparison to Nigella sativa L. in Streptozotocin Induced Diabetic Rats. Journal of M-Medicinal Plants Research, 5, 5779-5784.

[2] Pennathur, S. and Heinecke, J.W. (2007) Mechanisms for Oxidative Stress in Diabetic Cardiovascular Disease. Antioxidants and Redox Signaling, 9, 955-969. http://dx.doi.org/10.1089/ars.2007.1595

[3] Natheer, H.A. (2011) Oxidative Stress, Antioxidant Status and Lipid Profile in the Saliva of Type 2 Diabetics. Diabetes and Vascular Disease Research, 8, 22-28. http://dx.doi.org/10.1177/1479164110390243

[4] Amira, A.M.A. (2010) Oxidative Stress and Disease. Research Journal of Immunology, 3, 129-145. http://dx.doi.org/10.3923/rji.2010.129.145

[5] Samson, F.E. and Nelson, S.R. (2000) The Aging Brain, Metals and Oxygen Free Radicals. Cellular and Molecular Biology, 46, 699-707.

[6] Genet, S., Kale, R.K. and Baquer, N.Z. (2002) Alterations in Antioxidant Enzymes and Oxidative Damage in Experimental Diabetic Rat Tissues: Effect of Vanadate and Fenugreek (Trigonellafoenum graecum). Molecular Cellular Biochemistry, 236, 7-12. http://dx.doi.org/10.1023/A:1016103131408

[7] McKenney, J.M. (2001) Pharmacotherapy of Dyslipidemia. Cardiovascular Drugs and Therapy, 15, 413-422. http://dx.doi.org/10.1023/A:1013341606476

[8] Yang, R., Sh,i Y., Hao, G., Li, W. and Le, G. (2008) Increasing Oxidative Stress with Progressive Hyperlipidemia in Human: Relation between Malondialdehyde and Atherogenic Index. Journal of Clinical Biochemistry and Nutrition, 43,154-158. http://dx.doi.org/10.3164/jcbn.2008044

[9] Asadujjaman, M., Hossain, M.S., Khan, M.R.I., Anisuzzaman, A.S.M., Ahmed, M. and Islam, A. (2011) Antihyperglycemic and Glycogenesis Effects of Different Fractions of Brassica oleracea in Alloxan Induced Diabetic Rats. International Journal Pharmaceutical Science and Research, 2, 1436-1442.

[10] Malviya, N., Jain, S. and Malvia, S. (2010) Antidiabetic Potential of Medicinal Plants. Acta Poloniae Pharmaceutica-Drug Research, 6, 7113-7118.

[11] Matafome, P., Louro, T., Rodriques, L., Crisostomo, J., Nunes, E., Amaral, C., Monterio, P., Cipriano, A. and Seica, R. (2011) Metformin and Atorvastatin Combination Further Protect the Liver in Type 2 Diabetes with Hyperlipidaemia. Diabetes/Metabolism Research and Reviews, 27, 54-62.

[12] Sinha, A.K. (1972) Colorimetric Assay of Catalase. Analytical Biochemistry, 47, 389-394. http://dx.doi.org/10.1016/0003-2697(72)90132-7

[13] Misra, H.P. and Fridovich, I. (1972) The Role of Superoxide Anion in the Auto Oxidation of Epinephrine and a Simple Assay for Superoxide Dismutase. Journal of Biological Chemistry, 247, 3170-3175.

[14] Aronson, D. (2008) Hyperglycemia and the Pathobiology of Diabetic Complications. Advances in Cardiology, 45, 1-16. http://dx.doi.org/10.1159/000115118

[15] Aqil, S., Jaleel, A., Jaleel, F. and Basir, F. (2008) Comparison of Adiponectin in Ischemic Heart Disease versus Ischemic Stroke in Diabetic Patients. World Applied Science Journal, 3, 759-762.

[16] Vadivelan, R., Umasankar, P., Dipanjan, M., Dhanabal, S.P., Shanish, A., Satishkumar, M.N. and Elanko, K. (2011) Antidiabetic Activity of Madhumega Churanam (Siddha Formulation) in Alloxan Induced Diabetic Rats. Der Pharmacia Sinica, 2, 299-304.

[17] Anitha, N., Rao, J.V., Kavimani, S. and Himabindu, V. (2008) Pharmacodynamic Drug Interaction of Metformin with Statins in Rats. Journal of Pharmacology and Toxicology, 3, 408-413.

[18] Balasubramanian, R., Varadharajan, S., Kathale, A., Nagraj, L.M., Periyandavar, I., Nayak, U.P., Sharma, A., Bolmall, C. and Baliga, V.P. (2008) Assessment of the Efficacy and Tolerability of a Fixed Dose Combination of Atorvastatin 10 mg plus Metformin SR 500 mg in Diabetic Dyslipidaemia in Adult Indian Patients. Journal of the Indian Medical 
Association, 106, 464-467.

[19] Jenkins, D.J.A., Jenkins, A.L., Wolever, T.M.S., Vuksan, V. and Rao, A.V. (1995) Effect of Reduced Rat of Carbohydrate Absorption on Carbohydrate and Lipid Metabolism. European Journal of Clinical Nutrition, 49, S68-S73.

[20] Iams, S.G. and Wexler, B.C. (1997) Alloxan Diabetes in Spontaneously Hypertensive Rats: Gravimetric, Metabolic and Histopathological Alterations. British Journal of Experimental Pathology, 58, 177-199.

[21] Sharma, S.R., Dwivedi, S.K. and Swarup, D. (1996) Hypoglycaemic and Hypolipidaemic Effects of Cinnamomum tamala Nees Leaves. Indian Journal of Experimental Biology, 34, 372-374.

[22] Rajasekaran, A. and Kalaivani, M. (2011) Antioxidant Activity of Aqueous Extract of Monascus Fermented Indian Variety of Rice in High Cholesterol Diet Fed-Streptozotocin Diabetic Rats, an in Vivo Study. The International Journal of Current Scientific Research, 1, 35-38.

[23] Turko, I.V., Marcondes, S. and Murad, F. (2001) Diabetes Associated Nitration of Tyrosine and Inactivation of Succinyl-CoA: 3-Oxoacid CoA-Transferase. American Journal of Physiology Heart and Circulatory Physiology, 281, 2289-2294.

[24] Rosen, F., Roberts, N.R. and Nichol, C.A. (2007) Glucocorticosteroids and Transaminase Activity. I. Increased Activity of Glutamic Pyruvic Transaminase in Four Conditions Associated with Gluconeogenesis. Journal of Biological Chemistry, 234. 476-480.

[25] Day, C.P. (2002) Pathogenesis of Steatohepatitis. Best Practice and Research Clinical Gastroenterology, 16, 663-678. http://dx.doi.org/10.1053/bega.2002.0333

[26] Singh, N. and Gupta, M. (2007) Regeneration of Beta Cells in Islets of Langerhans of Pancreas of Alloxan Diabetic Rats by Acetone Extract of Momordica charantia (Linn.) (Bitter Gourd) Fruits. Indian Journal of Experimental Biology, 45, 1055-1062.

\section{Abbreviations}

ADRs
B.W
CVD
DM
EDTA
HDL-C
HMG-CoA
i.p
ICDDRB
LDL-C
mM
mmol/L
SD
SEM
SGOT
SGPT
SOD
TC
TG

Alloxan induced diabetic rats.

$$
\text { Body Weight }
$$

Cardio vascular diseases

Diabetis Mellitus

Ethyl Di Acetate Tetra acetic Acid

High density lipoprotein $\mathrm{C}$

3 hydroxyy-3 methyl-coenzyme A.

Intra-peritoneal

International centre for diarrheal disease research Bangladesh.

Low density lipoprotein C

$$
\begin{gathered}
\text { Milli Mole } \\
\text { Millimole/Liter } \\
\text { Standard deviation } \\
\text { Standard error mean }
\end{gathered}
$$

Serum glutamic pyruvate transaminase

Serum glutamic oxaloacetate transaminase

Super oxide dismutase

Total cholesterol

Triglycerides 
Scientific Research Publishing (SCIRP) is one of the largest Open Access journal publishers. It is currently publishing more than 200 open access, online, peer-reviewed journals covering a wide range of academic disciplines. SCIRP serves the worldwide academic communities and contributes to the progress and application of science with its publication.

Other selected journals from SCIRP are listed as below. Submit your manuscript to us via either submit@scirp.org or Online Submission Portal.
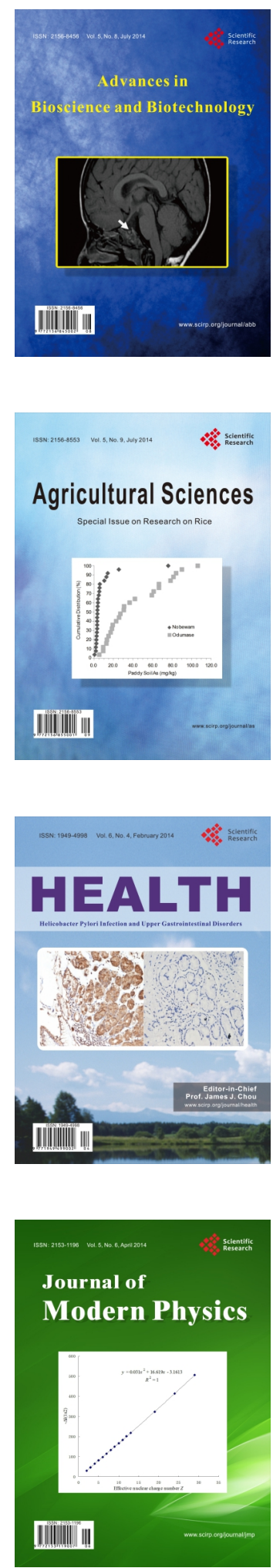
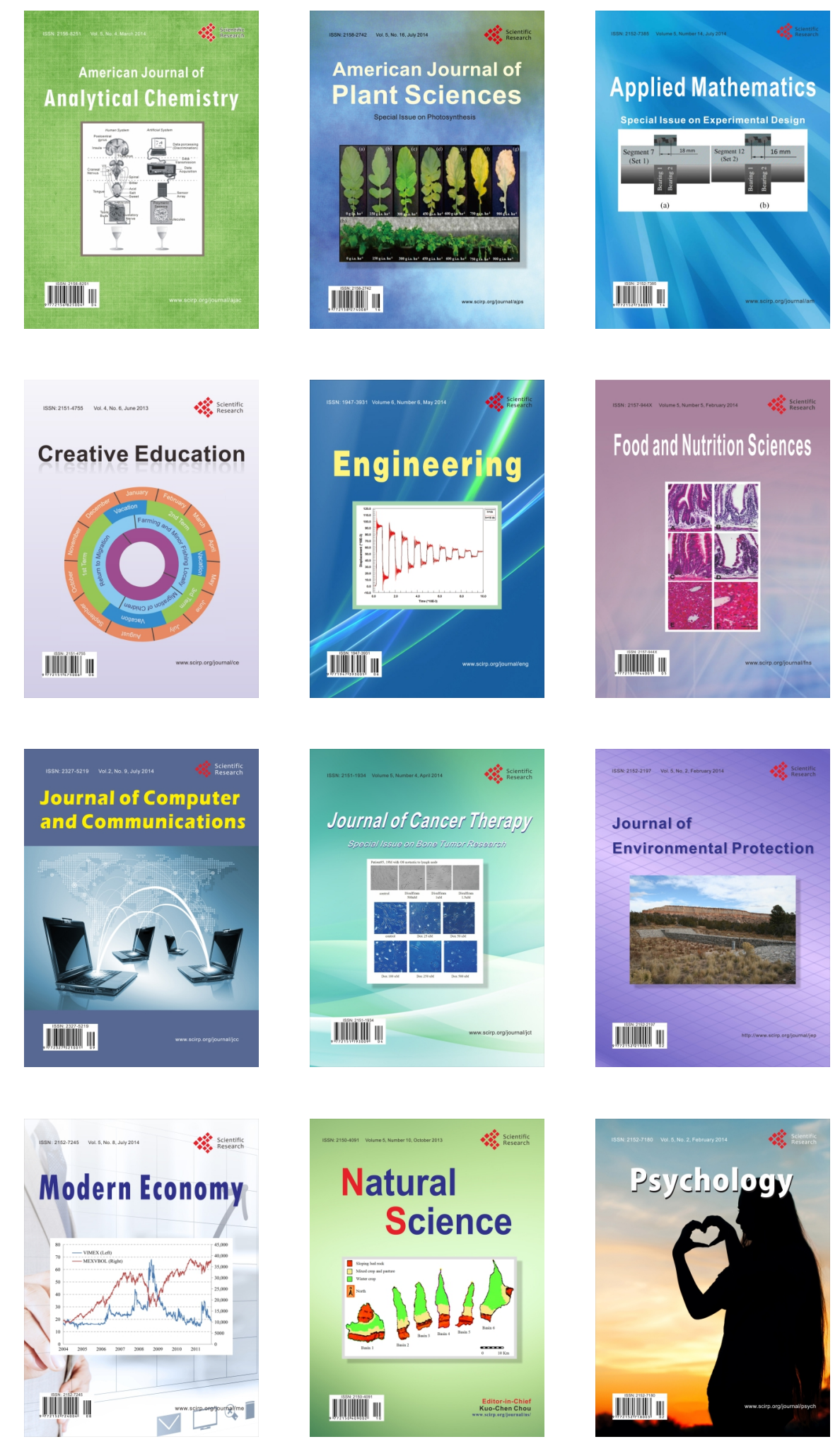